Proc. Estonian Acad. Sci. Eng., 2002, 8, 1, 52-57

\title{
Identification of the wheelbase of road vehicles from wheel speed signals
}

\author{
Péter Frank and Ansgar Fries
}

\begin{abstract}
Knorr-Bremse Research \& Development Centre, Major u. 69, H-1119 Budapest, Hungary; \{peter.frank,ansgar.fries\}@ knorr-bremse.com
\end{abstract}

Received 9 October 2001, in revised form 7 February 2002

\begin{abstract}
Electronically controlled brake systems are nowadays widely used in road vehicles. The control systems consist of sensors, actuators, and of the electronic control unit. To reduce the number of system components is a permanent market need. Therefore the intelligence of the control software should be improved. One direction of improvement is the implementation of adaptive algorithms. The latter allow to renounce some pre-programmed parameters. The paper presents a simple method for the identification of the wheelbase of road vehicles by evaluating the wheel speed signals only. The method uses the correlation between noisy speed signals of wheels running on the same road track one after another over a bump. Measurements carried out on heavy trucks show the practical value of the method.
\end{abstract}

Key words: electronically controlled brake system, road excitation, parameter identification, correlation.

\section{INTRODUCTION}

One possibility for cost reduction of electronically controlled brake systems is the reduction of the number of pre-programmed control parameters. Such parameters are the type of wheel-brakes, the wheelbase, etc. They are programmed at the end of the manufacturing line individually for each vehicle. Every purely software solution for on-line identification of these parameters reduces the duration of the programming and therefore the manufacturing costs.

Wheel-speed sensors are among the oldest and most robust elements of the antilock break systems (ABS) $\left[{ }^{1,2}\right]$. The sensor consists of a pole-wheel and an inductive sensor. The information content of the signals is nearly completely used by contemporary control systems. Different signal filtering methods and comparison of signals of different wheels permit identification of wheel locking, 
wheel spin-out, cornering, wheel diameter deviations, detection of different driving phases (e.g., traction, gearshift), sensor signal failures such as pole-wheel filling, etc. $\left[{ }^{3-5}\right]$. All this information content is, however, not completely used yet.

The suggested method permits estimation of the wheelbase by calculating the correlation between front and rear wheel speeds (Fig. 1).

\section{ESTIMATION OF THE WHEELBASE}

Figure 2 shows the wheel speeds of a truck during a simple maneuver where different driving phases are indicated. The wheel speeds are different during cornering. Acceleration represents the road inclination and forces of resistance during gearshifts. At the end of a gearshift, driveline excitation causes swinging $\left.{ }^{6}\right]$. Road excitation (bump) is also visible around the 43rd second.

The road excitation has a special feature in comparison to the other disturbances of wheel speed signals. Road-excited disturbances are repeated: first the speed signals of the front wheels are disturbed and later those of the rear ones. Time-lag between these disturbances depends on the vehicle speed and wheelbase. Since the vehicle speed is known from the wheel speed signals, the wheelbase can be estimated.

For identification of the wheelbase we need the correlation of the front and rear wheel speed signals or rather a common signal from both front and rear

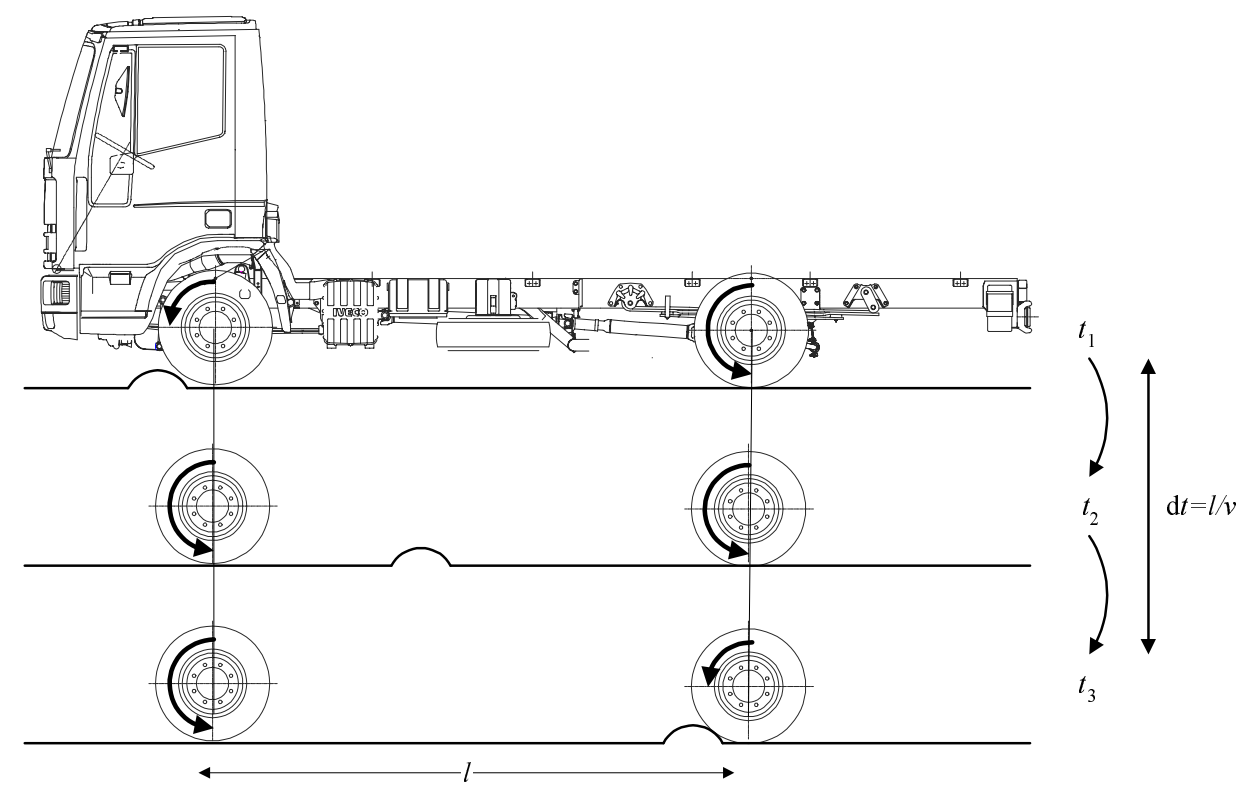

Fig. 1. Principle of the wheelbase estimation. 


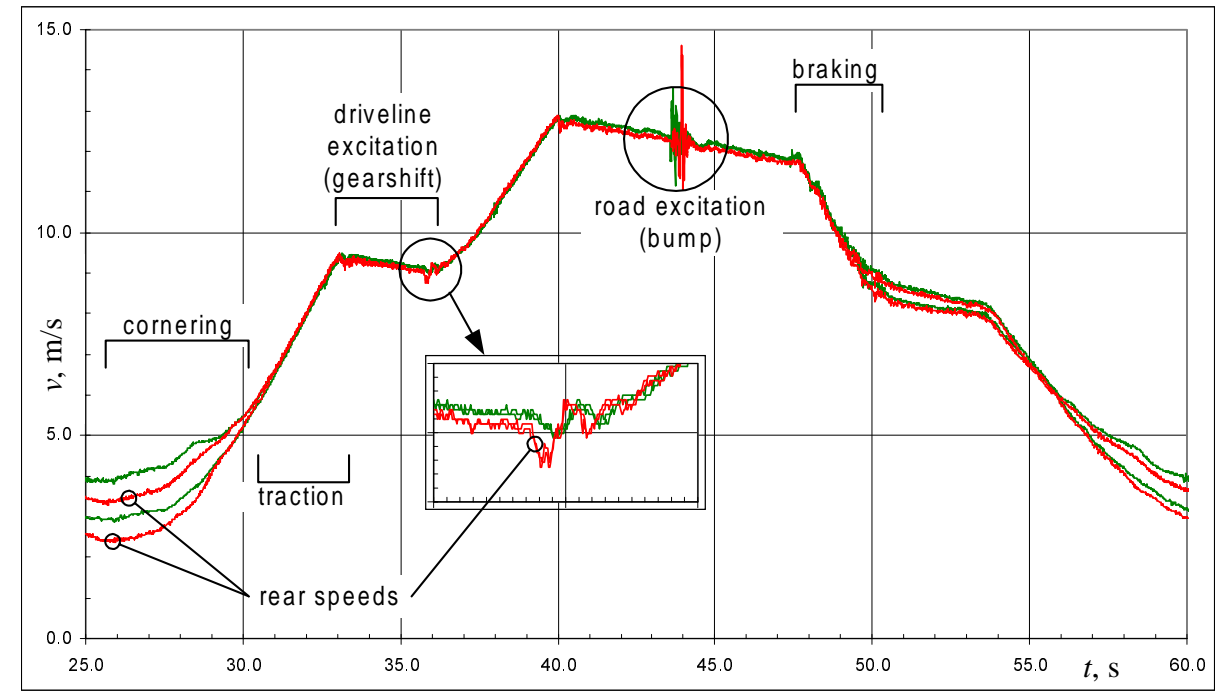

Fig. 2. Wheel speed signals of a truck during a simple maneuver.

wheel speeds, from which the autocorrelation can be calculated. Let us define the specific wheel speed difference as

$$
\Delta s=\frac{v_{\text {front }}-v_{\text {rear }}}{v_{\text {front }}},
$$

where $v$ indicates the wheel speeds

$$
v_{\text {front }}=\frac{v_{\text {front-left }}-v_{\text {front-right }}}{2}, \quad v_{\text {rear }}=\frac{v_{\text {rear-left }}-v_{\text {rear-right }}}{2} .
$$

The autocorrelation of $\Delta s$ can be defined as:

$$
\rho_{\Delta s}(t)=\frac{\int_{t_{0}}^{t_{1}}\left(\Delta s(\tau)-\mu_{\Delta s}\right)\left(\Delta s(\tau-t)-\mu_{\Delta s}\right) \mathrm{d} \tau}{\sigma_{\Delta s}^{2}},
$$

where $\mu_{\Delta s}$ is average $\Delta s$ over $\left[t_{0}, t_{1}\right]$ and $\sigma_{\Delta s}$ is standard deviation of $\Delta s$ over $\left[t_{0}, t_{1}\right]$.

The autocorrelation can be transferred to the distance domain, to get distanceautocorrelation of the specific wheel speed difference $\Delta s$ :

$$
\tilde{\rho}_{\Delta s}(l)=\frac{\int_{l_{0}}^{l_{1}}\left(\Delta \tilde{s}(\lambda)-\mu_{\Delta s}\right)\left(\Delta \tilde{s}(\lambda-l)-\mu_{\Delta s}\right) \mathrm{d} \lambda}{\tilde{\sigma}_{\Delta s}^{2}},
$$


where $\tilde{\sigma}_{\Delta s}^{2}$ is standard deviation of $\Delta s$ over $\left[l_{0}, l_{1}\right]$ and

$$
l(t)=\int_{t_{0}}^{t_{1}} v(t) \mathrm{d} t
$$

is the distance parameter.

This autocorrelation of $\Delta s$ is expected to obtain its extreme value when $l$ equals the wheelbase (strongest correlation). The disturbances of speed signals from the front and rear wheels have opposite signs, thus influencing $\Delta s$ in opposite directions. The extreme value is a minimum; thus the location of the maximum negative autocorrelation is to be determined.

\section{MEASUREMENT RESULTS}

Measurements were carried out to verify the accuracy of the wheelbase identification method. Two heavy trucks (Scania R124LB 6X2NB 420 with a wheelbase $3900 \mathrm{~mm}$ and Scania R124LA 4X2NA 420 with a wheelbase $3550 \mathrm{~mm}$ ) were used on bumpy roads. Wheel speed sensors of the installed electropneumatic brake system were measured with a PC-based data acquisition system. Figure 3 shows the influence of the road excitation on the wheel speed and specific speed difference signals.
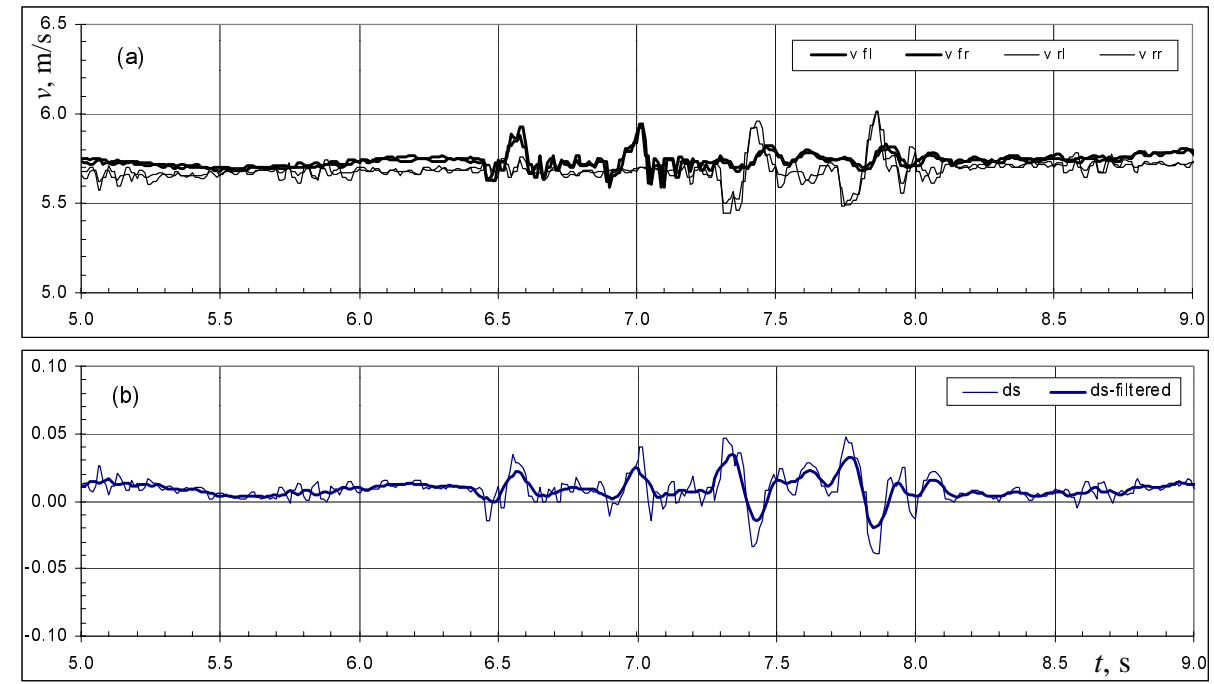

Fig. 3. (a) Wheel speed signals: thick curves - front wheels, thin curves - rear wheels; (b) specific speed difference during driving across a pair of bumps (average vehicle speed was $20.5 \mathrm{~km} / \mathrm{h}$ ): - direct signal, - slightly filtered signal. 
Autocorrelation of the specific wheel speed difference signal over a distance is presented in Fig. 4. The location of the minimum of this function gives the estimated value for the wheelbase. Estimated value is $4009 \mathrm{~mm}$, (real: $3900 \mathrm{~mm}$ ), relative error is $2.8 \%$.

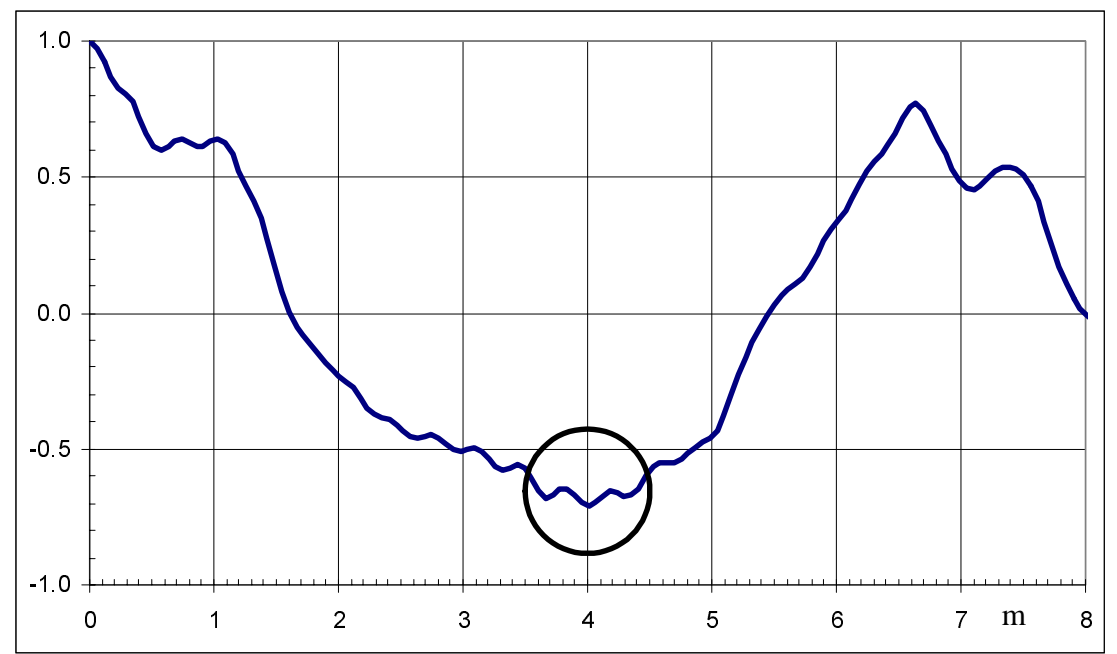

Fig. 4. Autocorrelation of the specific wheel speed difference vs distance. Minimum is located at the estimated value of the wheelbase.

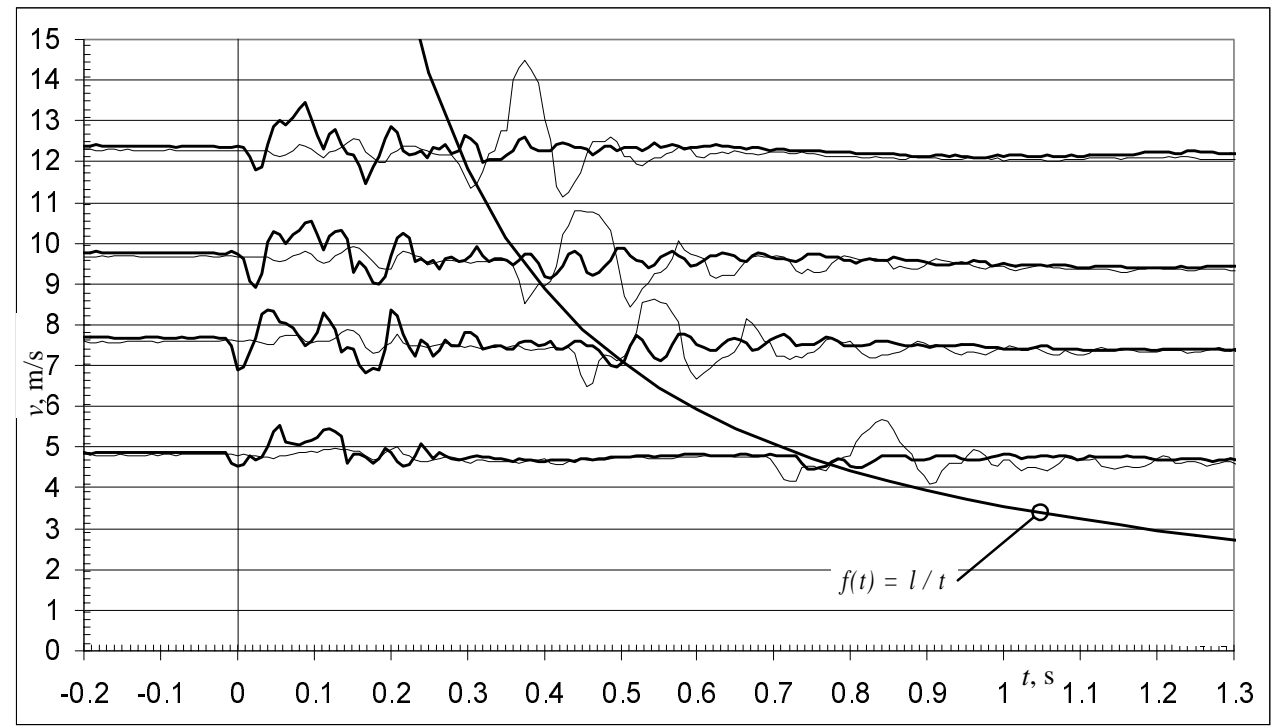

Fig. 5. Axle-averaged wheel speed signals of a vehicle running over a single bump with different driving speeds: - rear wheels, - front wheels. Time-delay between excitation of different axles depends on the driving speed. 
Figure 5 presents measurements at different vehicle speeds. Average speed of the front wheels and that of the rear wheels are presented for four different speed levels: $4.8,7.5,9.6$, and $12.3 \mathrm{~m} / \mathrm{s}$. The vehicle was running over a single bump. The origin of the time axis is shifted to the first instance of the road excitation. The curve $f(t)=l / t$ is also presented $(l=3550 \mathrm{~mm})$, showing the speed dependence of the delay of excitation of the axles.

\section{SUMMARY}

A simple method has been presented for on-line identification of the wheelbase from simple wheel speed sensor signals. Autocorrelation of the axle-wise specific wheel speed signals was calculated in the distance domain.

Measurement results showed an accuracy of about 3\% of the estimated wheelbase. Suitable accuracy can be achieved on roads containing single or double bumps. The results on real roads depend strongly on the road profile. A cheap and safe way of self-programming the truck's wheelbase parameter is driving over a doorstep after leaving the manufacturing line.

Existing control algorithms such as ABS yaw control can be improved using the identified wheelbase value.

\section{REFERENCES}

1. Burckhardt, M. Fahrwerktechnik: Radschlupf-Regelsysteme. Vogel Buchverlag, Würzburg, 1993.

2. von Glasner, E.-C. Fahr- und Bremsverhalten von Nutzfahrzeugen. In Lecture notes of Budapest University of Technology and Economics. Budapest, 1997.

3. Frank, P. Slip control at small slip values for road vehicle brake systems. Periodica Polytechnica, Mech. Eng., 2000, 44, 23-30.

4. Frank, P. Load-dependent control of braking forces on commercial vehicles. In Proc. First Conference on Mechanical Engineering, Gépészet '98. Springer Hungarica, Budapest, 1998, 1, 329.

5. Frank, P. Verfahren und Vorrichtung zur Bestimmung des Ansprechdrucks von Fahrzeugbremsen. German Patent Bulletin, DE10026688C1, Deutsches Patent- und Markenamt, 2001.

6. Zegelaar, P. W. A. and Pacejka, H. B. Dynamic tyre responses to brake torque variations. In Vehicle System Dynamics Supplement (Böhm, F. and Willumeit, H.-P., eds.), Vol. 27. Swets \& Zeitlinger B. V., Lisse, The Netherlands, 1997, 65-79.

\section{Mootorsõidukite telgedevahe määramine rataste kiiruse signaalide põhjal}

\section{Péter Frank ja Ansgar Fries}

On kirjeldatud mootorsõidukite telgedevahe määramise meetodit, mis baseerub esi- ja tagarataste kiiruse signaalide häiringute korrelatsioonil kunstliku teekühmu ületamise korral. 